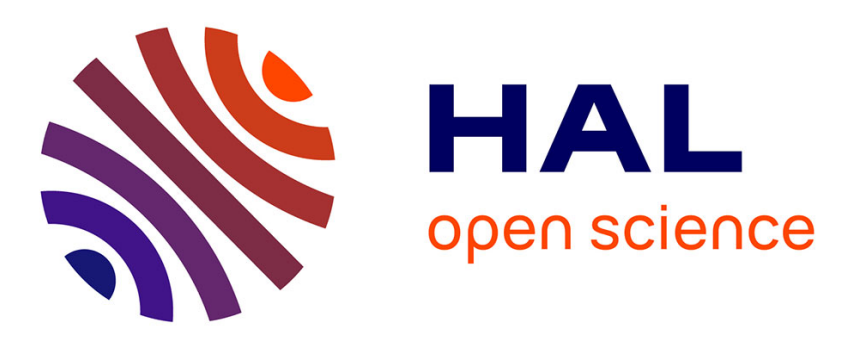

\title{
ENSO Effects on Annual Variations of Summer Precipitation Stable Isotopes in Lhasa, Southern Tibetan Plateau
}

Jing Gao, You He, Valerie Masson-Delmotte, Tandong Yao

\section{> To cite this version:}

Jing Gao, You He, Valerie Masson-Delmotte, Tandong Yao. ENSO Effects on Annual Variations of Summer Precipitation Stable Isotopes in Lhasa, Southern Tibetan Plateau. Journal of Climate, 2018, 31 (3), pp.1173-1182. 10.1175/JCLI-D-16-0868.1 . hal-02976442

\section{HAL Id: hal-02976442 \\ https://hal.science/hal-02976442}

Submitted on 9 Jun 2021

HAL is a multi-disciplinary open access archive for the deposit and dissemination of scientific research documents, whether they are published or not. The documents may come from teaching and research institutions in France or abroad, or from public or private research centers.
L'archive ouverte pluridisciplinaire $\mathbf{H A L}$, est destinée au dépôt et à la diffusion de documents scientifiques de niveau recherche, publiés ou non, émanant des établissements d'enseignement et de recherche français ou étrangers, des laboratoires publics ou privés. 


\title{
${ }^{\partial}$ ENSO Effects on Annual Variations of Summer Precipitation Stable Isotopes in Lhasa, Southern Tibetan Plateau
}

JING GAO

Key Laboratory of Tibetan Environment Changes and Land Surface Processes, Institute of Tibetan Plateau Research, and Center for Excellence in Tibetan Plateau Earth Sciences, Chinese Academy of Sciences, Beijing, China

You He

Key Laboratory of Tibetan Environment Changes and Land Surface Processes, Institute of Tibetan Plateau Research, Chinese Academy of Sciences, Beijing, China

VALERIE MASSON-DELMOTTE

LSCE, UMR 8212 CEA/CNRS/UVSQ-IPSL, Gif-sur-Yvette, France

\section{TANDONG YAO}

Key Laboratory of Tibetan Environment Changes and Land Surface Processes, Institute of Tibetan Plateau Research, and Center for Excellence in Tibetan Plateau Earth Sciences, Chinese Academy of Sciences, Beijing, China

(Manuscript received 10 December 2016, in final form 22 October 2017)

\begin{abstract}
Although El Niño-Southern Oscillation (ENSO) influences the Indian summer monsoon, its impact on moisture transport toward the southern Tibetan Plateau (TP) remains poorly understood. Precipitation stable isotopes are useful indices for climate change in the TP. Classical interpretations of variations of precipitation stable isotopes focus on the local surface air temperature or precipitation amount. However, several of the latest studies suggested they may correlate with large-scale modes of variability, such as ENSO. This paper presents a detailed study of ENSO's effect on annual variations of the oxygen stable isotopic composition of precipitation $\left(\delta^{18} \mathrm{O}_{p}\right)$ at Lhasa in the southern TP for up to 10 years. The stable isotopic composition of water vapor from satellite data [Tropospheric Emission Spectrometer (TES)] and simulations from an isotopically enabled atmospheric general circulation model (zoomed LMDZiso) are used to explore the mechanism that leads to variations of $\delta^{18} \mathrm{O}_{p}$ at Lhasa. Statistically significant correlations between $\delta^{18} \mathrm{O}_{p}$ and ENSO indices [Southern Oscillation index (SOI) and Niño-3.4 sea surface temperature index (Niño-3.4)] are observed. This paper shows that ENSO's effects on the location and intensity of convection over the Arabian Sea, the Bay of Bengal, and the tropical Indian Ocean, along moisture transport paths toward Lhasa, further impact convection from the northern Tibetan Plateau. The changing of this convection results in lower $\delta^{18} \mathrm{O}_{p}$ at Lhasa in 2007, a La Niña year, and higher $\delta^{18} \mathrm{O}_{p}$ in 2006, an El Niño year. The study presented here confirms that the regional upstream convection related to ENSO teleconnections plays an important role in variations of $\delta^{18} \mathrm{O}_{p}$ at the interannual scale and that the more depleted oxygen stable isotopic composition of vapor $\left(\delta^{18} \mathrm{O}_{v}\right)$ from the northwestern region of India during a La Niña year intensifies the lower $\delta^{18} \mathrm{O}_{p}$ at Lhasa in a La Niña year. The study's results have implications for the interpretation of past variations of archives with precipitation stable isotopes, such as ice cores, tree rings, lake sediments, and speleothems, in this region.
\end{abstract}

Denotes content that is immediately available upon publication as open access.

Supplemental information related to this paper is available at the Journals Online website: https://doi.org/JCLI-D-16-0868.s1.

Corresponding author: Jing Gao gaojing@itpcas.ac.cn

\section{Introduction}

El Niño-Southern Oscillation (ENSO) is a well-known climatic phenomenon affecting the interannual variability of the Indian summer monsoon (Annamalai et al. 2007; Kumar et al. 1999; Torrence and Webster 1999), with large decadal variability in the ENSO-monsoon relationship (Kumar et al. 1999; Li and Ting 2015). 
Previous studies suggested that the western Pacific SSTs dominate the relationship between the ENSO phase and tropical convection in the Bay of Bengal (Felton et al. 2013; Girishkumar and Ravichandran 2012; Girishkumar et al. 2015; Soman and Slingo 1997) and the Asian summer monsoon (Fan et al. 2016; Meehl and Arblaster 2002). El Niño and La Niña are the warm and cold phases of ENSO, respectively, and are associated with different characteristics of SST and tropical convection via the modulation of the Walker circulation or the Hadley circulation (Felton et al. 2013; Fan et al. 2016; Vuille and Werner 2005). In addition, ENSO impacts the onset date of the South Asian summer (e.g., June-September) monsoon (SASM) over the southwestern region of India (Kerala) by modulating the vertical coupling of the different levels of circulation over South Asia (Goswami and Xavier 2005; Liu et al. 2015; Mao and Wu 2007). El Niño shortens the length of the rainy season for the South Asian monsoon (Goswami and Xavier 2005) and appears to have the opposite effect on Indian summer monsoon rainfall (e.g., frequently there is weak Indian summer monsoon rainfall during an El Niño event and strong Indian summer monsoon rainfall during a La Niña event) (Boschat et al. 2011). In addition, previous studies have suggested that the zonal circulation [i.e., Indian Ocean dipole (IOD)] could significantly reduce the impact of ENSO on Indian summer rainfall related to the phase (positive/negative) that co-occurs as a result of the abnormal convection activities over the western Pacific/ western part of the tropical Indian Ocean (Ashok et al. 2004, 2001; Sankar et al. 2011).

The ENSO signal could be probed at the interannual scale using ice core records in the Tibetan Plateau (TP), but there is only a weak statistical relationship between ice core $\delta^{18} \mathrm{O}$ and the ENSO index (Thompson et al. 2000a; Yang et al. 2000). Here, we try to clarify the impact of ENSO on the precipitation isotopic composition $\left(\delta^{18} \mathrm{O}_{p}\right)$ in the southern TP and the underlying mechanisms. Recent studies have been focused on mechanisms of intra-annual variability of the south Tibetan precipitation $\delta^{18} \mathrm{O}_{p}$, combining in situ monitoring, back trajectories, remote sensing, and atmospheric modeling (Gao et al. 2013; He et al. 2015; Yao et al. 2013). Day-to-day $\delta^{18} \mathrm{O}_{p}$ variations were shown to reflect the integrated effect of initial vapor conditions, moisture transport (by the Indian summer monsoon and the westerlies), and processes along the moisture transport path (Gao et al. 2013, 2011; Tian et al. 2001; Yao et al. 2013). At interannual and longer time scales, variations in TP precipitation stable isotopes are related to changes in local climate variables (temperature or precipitation amount) (Cai and Tian 2016) and the large-scale atmospheric circulation (Gao et al. 2016;
Tian et al. 2003), including ENSO (Thompson et al. 2000b) and the Atlantic Oscillation (AO), which are involved in a seesaw pattern in atmospheric pressure between the North Pole and middle northern latitudes related to changes of the westerlies and a teleconnection with ENSO. However, the exact mechanisms by which ENSO impacts the isotopic composition of precipitation in the southern TP were not previously identified.

The goals of this paper are to detect the possible impact of ENSO on the precipitation stable isotopes in the southern TP and to explore the mechanisms that drive the annual variation of precipitation stable isotopes in this region. Our study uses 10 -yr event-based observations at Lhasa $\left(29.70^{\circ} \mathrm{N}, 91.13^{\circ} \mathrm{E} ; 3658 \mathrm{~m}\right)$ and the ENSO index. The mechanisms relating ENSO and $\delta^{18} \mathrm{O}_{p}$ are assessed using those datasets with simulations from an atmospheric general circulation model equipped with water stable isotopes (the zoomed LMDZiso model), as well as information from remote sensing for the water vapor isotopic composition $\left(\delta^{18} \mathrm{O}_{v}\right)$ [from the Tropospheric Emission Spectrometer (TES)] and outgoing longwave radiation (OLR). It is noted that 2006 is classified as a weak El Niño event, which is focused on in this study, and we cannot choose strong events because of the limit of synchronously available TES and observation data. Section 2 describes our datasets and methods. Section 3 presents the relationship between interannual variations in Lhasa $\delta^{18} \mathrm{O}_{p}$ and the ENSO index, and investigates the underlying mechanisms. Finally, our conclusions are summarized in section 4 .

\section{Data and methods}

Lhasa is located in a vast valley near the Brahmaputra River. The Indian summer monsoon is the dominant moisture transport in this region. Eventbased precipitation samples were collected at Lhasa from 1997 to 2007. After 2007, observed data are not available so far. Because the amount of summer [JuneSeptember (JJAS)] precipitation accounts for about $85 \%$ of the annual precipitation amount, only the events that occurred in JJAS are discussed in the paper. All samples were measured by a MAT-253 mass spectrometer (precision of $0.2 \%$ ) in the Laboratory of Ice Core and Cold Regions Environment of the Cold and Arid Regions Environmental and Engineering Research Institute, Lanzhou, China. The earlier review study on TP precipitation stable isotopes was based on these data (Yao et al. 2013). Here, we use precipitation $\delta^{18} \mathrm{O}_{p}$, precipitation amount, and surface air temperature from Lhasa. In this study, monthly and annual 
TABLE 1. Number of daily events in each month used in this study.

\begin{tabular}{lcccc}
\hline \hline Year & June & July & August & September \\
\hline 2005 & 8 & 14 & 21 & 11 \\
2006 & 14 & 11 & 16 & 7 \\
2007 & 9 & 18 & 17 & 10 \\
\hline
\end{tabular}

$\delta^{18} \mathrm{O}_{p}$ are calculated from the event-based data by precipitation amount weighting as $\delta^{18} \mathrm{O}_{w}=\sum_{1}^{n} \delta_{i} P_{i} / \sum_{1}^{n} P_{i}$, where this indicates the amount of weighted $\delta^{18} \mathrm{O}_{w} ; \delta_{i}$ and $P_{i}$ refer to $\delta^{18} \mathrm{O}_{p}$ and the corresponding amount, respectively, and $n$ indicates the number of events occurring daily (Table 1 ). JJAS $\delta^{18} \mathrm{O}_{p}$ values are the precipitation amount weighted mean $\delta^{18} \mathrm{O}_{p}$ from June to September in each year.
TES data provide the deuterium content of water vapor $\left(\delta \mathrm{D}_{v}\right)$ from satellite measurements with a precision of $10 \%-15 \%$ for the individual measurement and a footprint of $5.3 \mathrm{~km} \times 8.5 \mathrm{~km}$. Worden et al. (2004, 2006, 2007) described the TES measurements and the retrieval methods in detail. The uncertainty and the sensitivity of the retrievals are discussed in detail in earlier studies (Risi et al. 2010), demonstrating that TES data are valuable for precipitation stable isotopes studies on the Tibetan Plateau (He et al. 2015). The valid TES data are available from 2005 only. Here we use the $\delta \mathrm{D}_{v}$ retrieved by TES at $680 \mathrm{hPa}$, which is the most sensitive level over the TP during summer, combined with in situ $\delta^{18} \mathrm{O}_{p}$ at Lhasa from 2005 to 2007. After quality control, 122 days of valid TES measurements are identified from 2005 to 2007 at Lhasa. Here, we
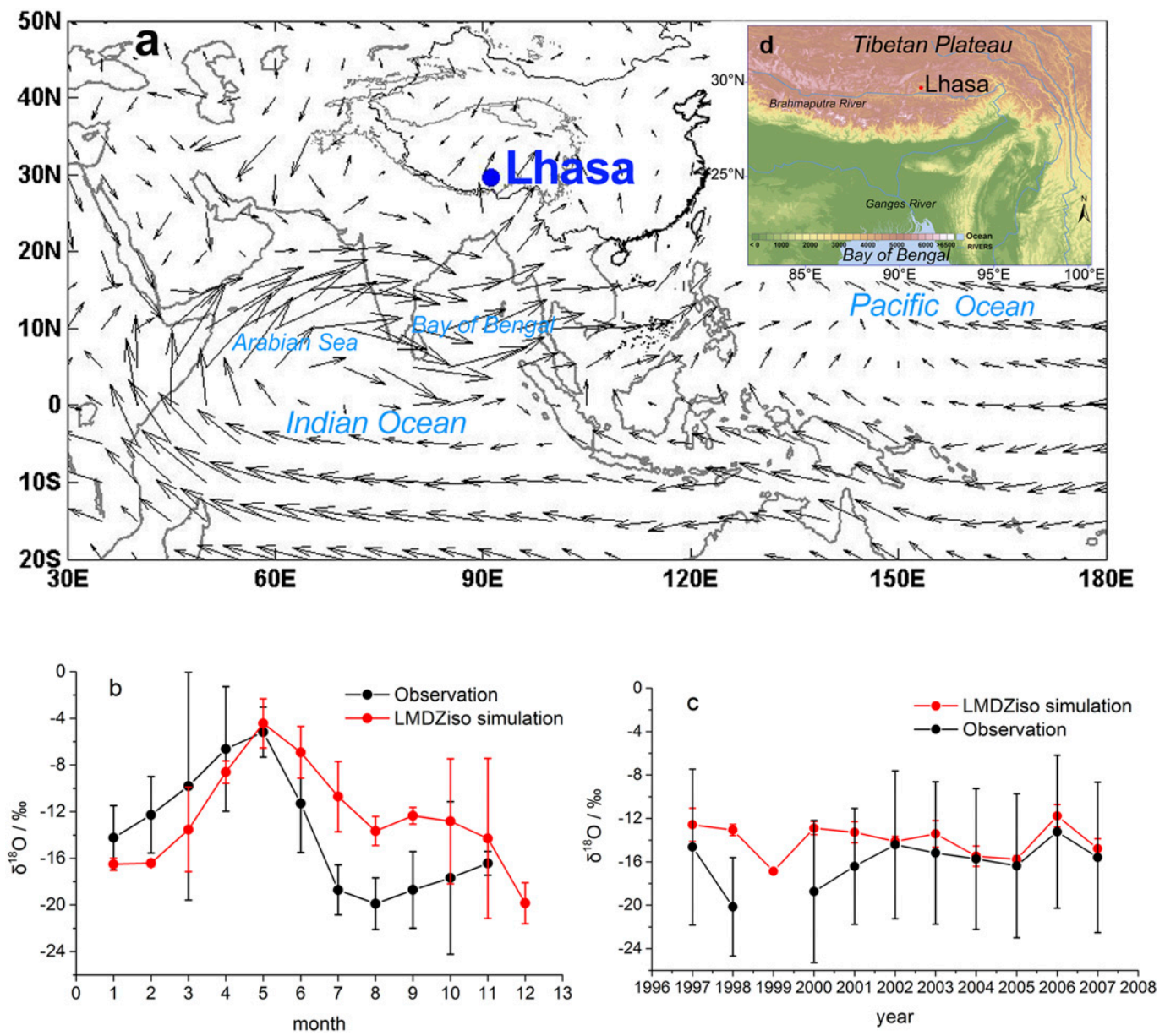

FIG. 1. (a) Averaged wind vectors from the period 1997-2007 at $850 \mathrm{hPa}$ (arrows) depicting the Indian monsoon flow in JJAS. Location of Lhasa is indicated. (b) Comparison of seasonal patterns of $\delta^{18} \mathrm{O}_{p}$ at Lhasa between station observations and simulations from zoomed LMDZiso (average monthly values from 1997 to 2007). Vertical error bars display the interannual monthly standard deviations. (c) As in (b), but for interannual variations in JJAS average $\delta^{18} \mathrm{O}_{p}$ from 1997 to 2007. Because of the lack of observations in 1999, no value is reported. (d) A zoomed DEM of the Lhasa region. 
TABLE 2. Linear regression analysis of interannual variations in JJAS $\delta^{18} \mathrm{O}_{p}$ at Lhasa, local climate, and indices of circulation and modes of variability. The variable $P$ is precipitation amount, and $T$ is surface air temperature. The bold values are statistically significant.

\begin{tabular}{|c|c|c|c|c|c|c|}
\hline \multirow{2}{*}{$\frac{\text { Climate indices }}{P}$} & \multicolumn{3}{|c|}{ Observed $\delta^{18} \mathrm{O}_{p}$} & \multicolumn{3}{|c|}{ Simulated $\delta^{18} \mathrm{O}_{p}$} \\
\hline & $y=-0.01 x-13.94$ & $R=-0.44$ & $p>0.05$ & $y=0.01 x-15.57$ & $R=0.22$ & $p>0.05$ \\
\hline$T$ & $y=0.15 x-24.82$ & $R=0.2$ & $p>0.05$ & $y=0.6 x-15.46$ & $R=0.19$ & $p>0.05$ \\
\hline SOI & $y=-0.22 x-16.78$ & $R=-0.82$ & $p<0.05$ & $y=-0.05 x-14.15$ & $R=-0.25$ & $p>0.05$ \\
\hline Niño-3.4 & $y=2.16 x-76.51$ & $R=0.73$ & $p<0.05$ & $y=0.63 x-31.08$ & $R=0.31$ & $p>0.05$ \\
\hline IOD & $y=4.11 x-17.20$ & $R=0.51$ & $p>0.05$ & $y=2.81 x-14.79$ & $R=0.44$ & $p>0.05$ \\
\hline $\mathrm{AO}$ & $y=0.01 x-17.27$ & $R=0$ & $p>0.05$ & $y=0.79 x-14$ & $R=0.1$ & $p>0.05$ \\
\hline ISM & $y=-0.57 x-13.09$ & $R=-0.21$ & $p>0.05$ & $y=-0.18 x+163.43$ & $R=-0.2$ & $p>0.05$ \\
\hline
\end{tabular}

focus on the temporal variability of $\delta \mathrm{D}_{v}$ retrievals, rather than on absolute values.

Daily OLR data with a resolution of $2.5^{\circ} \times 2.5^{\circ}$ are used here as an index of tropical deep convection (Liebmann and Smith 1996; Zhang 1993; Fu et al. 1990) from 2005 to 2006, and GPCP precipitation data with a spatial resolution of $1^{\circ} \times 1^{\circ}$ are also used to quantify the precipitation amounts along moisture transport paths (Huffman et al. 2001).

The airmass transport paths are calculated using the Hybrid Single-Particle Lagrangian Integrated Trajectory model (HYSPLIT) (Draxler and Hess 1998) based on the National Centers for Environmental Predication (NCEP) reanalysis data (Kalnay et al. 1996). Back trajectories at 6-h time steps for 5 days prior to arriving in Lhasa were computed at $1000 \mathrm{~m}$ AGL from 2005 to 2007 when TES data were available.

The zoomed LMDZiso atmospheric general circulation model developed at the Laboratoire de Météorologie Dynamique (LMD) is forced by observed sea surface temperature (SST) and sea ice following the Atmospheric Model Intercomparison Project protocol (Gates 1992) and is nudged by the three-dimensional horizontal winds from European Centre for Medium-Range Weather Forecasts (ECMWF) operational analyses (Klinker et al. 2000). It is used with a horizontal resolution of about $50 \mathrm{~km}$ around the TP and is equipped with water stable isotopes as described in Risi et al. (2010). Simulations from this model were used in earlier studies of precipitation stable isotopes on the Tibetan Plateau (Gao et al. 2011; He et al. 2015; Yao et al. 2013).

The Southern Oscillation index (SOI), defined as the anomalous low sea level pressure (SLP) in the eastern Pacific at Tahiti $\left(17.6^{\circ} \mathrm{S}, 149.6^{\circ} \mathrm{W}\right)$ minus SLP in the western Pacific at Darwin, Australia $\left(12.4^{\circ} \mathrm{S}, 130.9^{\circ} \mathrm{E}\right)$, indicates the development and intensity of ENSO in the Pacific Ocean (Keppenne and Ghil 1992; http:// www.bom.gov.au/climate/current/soihtm1.shtml). SOI values lower than -7 indicate El Niño episodes, while values greater than 7 indicate La Niña episodes. The Niño-3.4 SST index (Rasmusson and Carpenter 1982; http://www.cpc.ncep.noaa.gov/data/indices/) is the most commonly used index to define ENSO, defined as the area-averaged SST from $5^{\circ} \mathrm{S}$ to $5^{\circ} \mathrm{N}$ and from $170^{\circ}$ to $120^{\circ} \mathrm{W}$ (Rayner et al. 2003). Positive values indicate $\mathrm{El}$ Niño events and negative values indicate La Niña events. Considering the possible teleconnections between ENSO, the Indian summer monsoon, and the AO, three other indices are also discussed in this study. The Indian summer monsoon (ISM) index (Kalnay et al. 1996; http:// www.esrl.noaa.gov/psd/data/gridded/) is defined using the difference between the 850-hPa zonal wind averaged over the southern Arabian Sea (SAS) from $5^{\circ}$ to $15^{\circ} \mathrm{N}$ and from $40^{\circ}$ to $80^{\circ} \mathrm{E}$ and that averaged over the northern region from $20^{\circ}$ to $30^{\circ} \mathrm{N}$ and from $70^{\circ}$ to $90^{\circ} \mathrm{E}$, reflecting the large-scale rainfall variability of the Indian summer monsoon (Wang et al. 2009). The AO index is used to describe the surface signature of modulations in the strength of the polar vortex aloft (Thompson and Wallace 1998; http:// www.cpc.ncep.noaa.gov/products/precip/CWlink/daily_ao_ index/ao.shtml). The IOD index is defined as the SST difference between the western Indian Ocean (i.e., the Arabian Sea) and the eastern Indian Ocean (i.e., south of Indonesia) (Saji and Yamagata 2003), and a positive IOD normally leads to droughts over the Indonesian region and strong convection over East Africa.

Considering the availability of the different datasets, we employed a case study for the 2005-07 period, where 2005 is a normal year, 2007 is a typical La Niña event, and 2006 is a typical El Niño event. ENSO-neutral conditions appeared during April-June 2005, and the El Niño event occurred from August to October 2006 and dissipated during January-February 2007. La Niña conditions developed from July 2007 to June 2008.

\section{Results}

\section{a. Relationships between annual $\delta^{18} O_{p}$ and ENSO indices}

Summer precipitation at Lhasa is mainly associated with the Indian summer monsoon, which brings moisture from the Bay of Bengal, the Arabian Sea, and the Indian Ocean (Fig. 1a). The $\delta^{18} \mathrm{O}_{p}$ exhibits an anteverted Z-shape seasonal variability with a seasonal amplitude of 

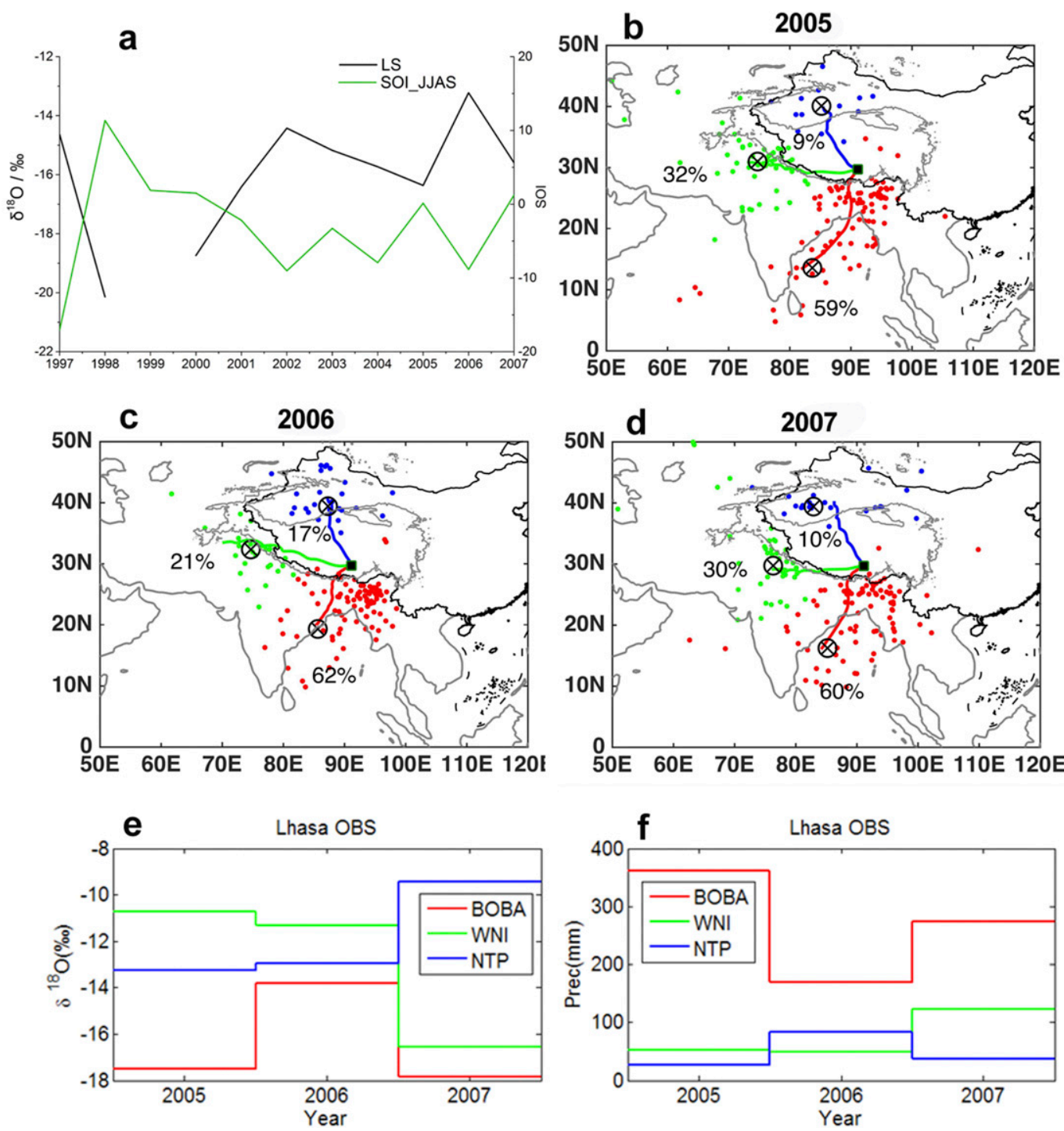

FIG. 2. (a) Relationship between the observed interannual JJAS $\delta^{18} \mathrm{O}_{p}$ at Lhasa and the SOI. (b)-(d) Back trajectories simulated by HYSPLT for Lhasa in 2005-07. Percentage shows the frequency of each clustered back trajectory, and circles show the central location of each clustered back trajectory. Dots show the location of each back trajectory, and the color refers to the clustered classification (i.e., BOBA in red, WNI in green, and NTP in blue). (e) Arithmetic mean values of event-based $\delta^{18} \mathrm{O}_{p}$ at Lhasa for each clustered back trajectory in 2005-07.

(f) Sum of the event-based precipitation amounts at Lhasa for each clustered back trajectory in 2005-07.

around $14 \%$. The $\delta^{18} \mathrm{O}_{p}$ increases beginning in January, and the highest $\delta^{18} \mathrm{O}_{p}$ is observed in May, whereas the $\delta^{18}$ $\mathrm{O}_{p}$ depletion occurs in June and reaches a minimum in August. A second increase is exhibited from September to November. The seasonal pattern of $\delta^{18} \mathrm{O}_{p}$ is captured by the zoomed LMDZiso, although with a slight overestimation of the summer $\delta^{18} \mathrm{O}_{p}$ (Fig. 1b). During the period from 1997 to 2007, maximum JJAS $\delta^{18} \mathrm{O}_{p}$ is observed in 2006, and minimum JJAS $\delta^{18} \mathrm{O}_{p}$ is observed in 1998; the difference of JJAS $\delta^{18} \mathrm{O}_{p}$ between these two years is $7 \%$. At the interannual scale, the zoomed LMDZiso is able to simulate features of the observed interannual variation of summer $\delta^{18} \mathrm{O}_{p}$ at Lhasa with a correlation coefficient of 0.7 (Fig. 1c), with better performance after 2002. The large deviation in Fig. 1b may result from the missed observation in 1999 and the imperfect matching between observations and simulations in 1998 and 2000. The TES data that are available since 2005 are also comparable with simulations from the zoomed LMDZiso with a correlation coefficient of 0.6 ( $p<0.1$; not shown). Thus, simulations from the zoomed LMDZiso and TES data can be used in this study. 
a Diff $\delta D_{v}$ at $680 \mathrm{hPa} \quad 2005-2006$ from observations

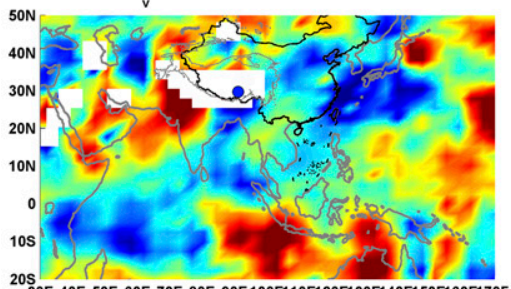

20S 30E 40E 50E 60E 70E 80E 90E100E110E120E130E140E150E160E170E

C Diff $\delta D_{v}$ at $680 \mathrm{hPa} 2005-2006$ from simulations

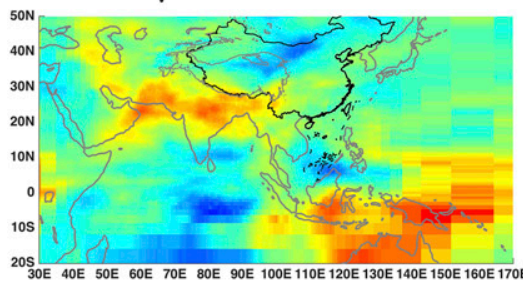

20S 30 E 40E 50E $60 \mathrm{E}$ 70E 80E 90E 100E $110 \mathrm{E}$ 120E $130 \mathrm{E}$ 140E $150 \mathrm{E}$ 160E 170

e Diff GPCP 2005-2006

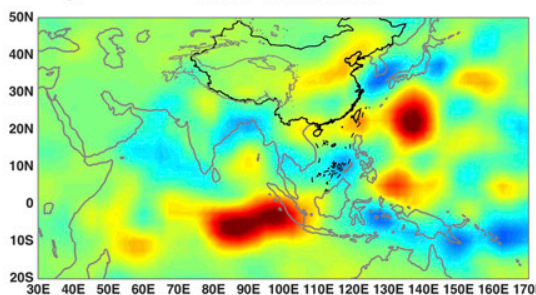

Diff OLR 2005-2006

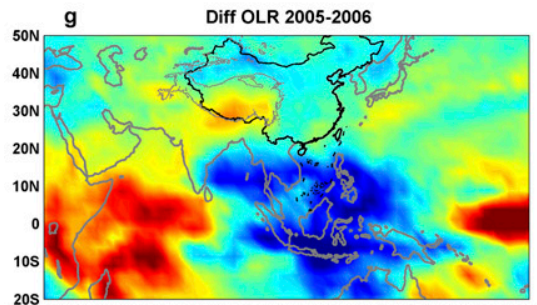

20S 30E 40E 50E 60E 70E 80E 90E 100E110E120E130E140E150E160E170E180
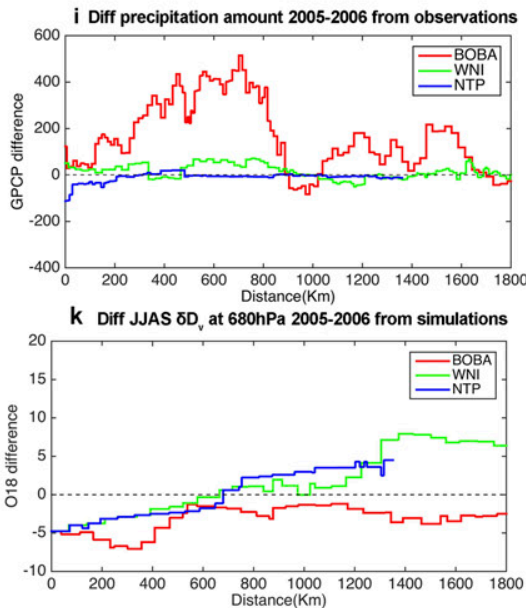

b Diff $\delta \mathrm{D}_{\mathrm{v}}$ at $680 \mathrm{hPa}$ 2007-2006 from observations

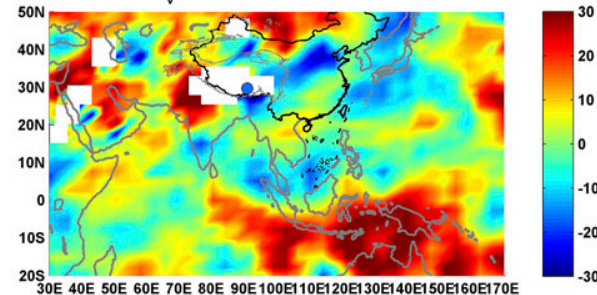

d Diff $\delta \mathrm{D}_{\mathrm{v}}$ at $680 \mathrm{hPa} 2007-2006$ from simulations

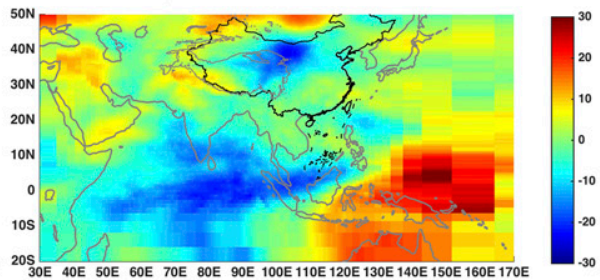

Diff GPCP 2007-2006
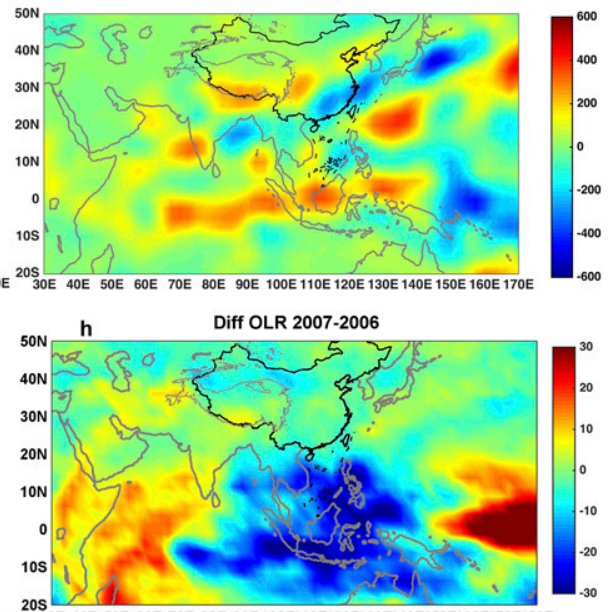

3OE 40E 50E 6OE TOE 80E 90E 100E110E120E130E140E150E160E170E180E

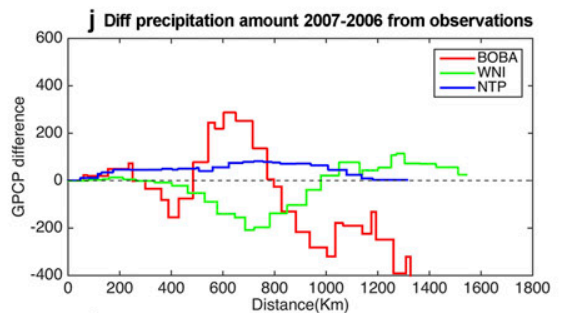

I Diff JJAS $\delta D_{y}$ at $680 \mathrm{hPa} 2007-2006$ from simulations

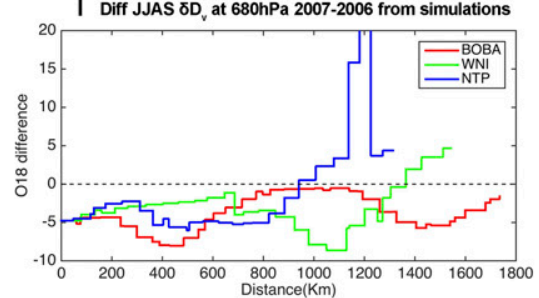

FIG. 3. (a) Difference in averaged JJAS $\delta \mathrm{D}_{v}$ at $680 \mathrm{hPa}$ from TES data between 2005 and 2006. The circle shows the location of Lhasa, and the color shows the difference of averaged JJAS $\delta^{18} \mathrm{O}_{p}$ at Lhasa from in situ observations. (b) As in (a), but for 2007 and 2006. We compare 2005-06 and 2007-06 to check the robustness of our results, and compare outputs from zoomed LMDZiso simulations with results from TES. (c) Difference in averaged JJAS $\delta \mathrm{D}_{v}$ at $680 \mathrm{hPa}$ from zoomed LMDZiso simulations between 2005 and 2006. (d) As in (c), but for 
The local surface air temperature and precipitation amount are thought to be generally remarkable factors that impact $\delta^{18} \mathrm{O}_{p}$ in the southern TP (Yao et al. 2013; Gao et al. 2013). However, no statistical relationship can be identified between JJAS $\delta^{18} \mathrm{O}_{p}$ and the corresponding local precipitation amount or the local surface air temperature at Lhasa for observations from 1997 to 2007 (Table 2). A significant negative correlation is shown between JJAS $\delta^{18} \mathrm{O}_{p}$ and SOI $(R=-0.82 ; P<0.05)$ during 1997-2007 (Fig. 2a); meanwhile, a prominent correlation is shown between JJAS $\delta^{18} \mathrm{O}_{p}$ and Niño-3.4 SST $(R=0.73 ; P<$ $0.05)$. No significant correlations can be identified with any other indices [e.g., westerly shear index (WSI1), AO, IOD, and ISM]. This suggests that ENSO is the main driver of interannual variations in JJAS $\delta^{18} \mathrm{O}_{p}$ at Lhasa. Simulations from the zoomed LMDZiso model produced similar results, although the model underestimated these correlations between JJAS $\delta^{18} \mathrm{O}_{p}$ and each index (Table 2).

\section{b. Mechanisms of teleconnections between ENSO and southern TP JJAS $\delta^{18} O_{p}$}

Here we combine the in situ observations, TES data, zoomed simulations, and reanalysis data to explore the mechanism of the teleconnection between ENSO and annual JJAS $\delta^{18} \mathrm{O}_{p}$ at Lhasa. The $\delta^{18} \mathrm{O}_{p}$ during the 2007 La Niña year is on average $-2.3 \%$ more depleted than during the $2006 \mathrm{El}$ Niño year, which is identified with a discrepancy of $\delta^{18} \mathrm{O}_{p}$ during the 1998 strong La Niña year and the 1997 strong El Niño year (on average - 5.5\%; Fig. 2a).

We use HYSPLIT to calculate back trajectories to Lhasa at $1000 \mathrm{~m}$ AGL for all days when rain events occurred from 2005 to 2007. HYSPLIT uses NCEP reanalysis data and computes trajectories with a 6-h time step back to 5 days. Results are then clustered into three paths (Figs. 2b-d), that is, moisture originating from the Bay of Bengal (BOBA), from the northwestern region of India (NWI), and from the northern region of the TP (NTP).

Most trajectories originate from BOBA, with a proportion that remains almost constant in 2005-07 (62\% during the $2006 \mathrm{El}$ Niño year, 59\% during the 2005 normal year, and $60 \%$ during the 2007 La Niña year). The ENSO phase appears to affect only the relative proportion of trajectories from NWI and NTP, with the proportion of NTP trajectories decreasing from $17 \%$ during the El Niño year to $9 \%$ during the normal year and almost $10 \%$ during the La Niña year (Figs. 2b-d). However, considering the $\delta^{18} \mathrm{O}_{p}$ associated with these trajectories, this proportion change does not explain the more depleted $\delta^{18} \mathrm{O}_{p}$ values (about $4 \%$; Fig. 2e) observed during the 2007 La Niña year.

We now focus on the $\delta^{18} \mathrm{O}_{p}$ at Lhasa and the precipitation amount along BOBA trajectories (Figs. 2e and 2f). BOBA trajectories during the $2007 \mathrm{La}$ Niña year lead to $4 \%$ more depleted $\delta^{18} \mathrm{O}_{p}$ than during the $2006 \mathrm{El}$ Niño year at Lhasa. A higher precipitation amount appeared during the 2005 normal year than during the 2007 La Niña year from the BOBA trajectory, but $\delta^{18} \mathrm{O}_{p}$ during the 2005 normal year is on average enriched $0.5 \%$ compared with that during the 2007 La Niña year at Lhasa. This may result from the change in the moisture origin along BOBA, which is discussed in the next section. Moisture trajectories from BOBA fall mostly over land in 2006, while more BOBA trajectories fall over water in 2007. This may result in enriched $\delta^{18} \mathrm{O}_{p}$ along BOBA in 2006. Because of the average $-2.3 \%$ difference in annual $\delta^{18} \mathrm{O}_{p}$ between 2007 and 2006 (Fig. 2a), we deduced that changes in the NTP trajectory resulted in the $1.7 \%$ enrichment of $\delta^{18} \mathrm{O}_{p}$. The change in precipitation amount of about $100 \mathrm{~mm}$ from the NWI and NTP trajectories may result in more than a $3 \%$ change in $\delta^{18} \mathrm{O}_{p}$ at Lhasa between the 2007 La Niña year and the 2005 normal year (Figs. 2e and 2f). This implies that ENSOinfluenced processes along the moisture path to Lhasa impact the interannual variations in the final $\delta^{18} \mathrm{O}_{p}$ values. The BOBA trajectory determines the overall features of $\delta^{18} \mathrm{O}_{p}$ at Lhasa, while the NWI and NTP trajectories show remarkably opposite impacts on $\delta^{18} \mathrm{O}_{p}$ in ENSO events. Given the current knowledge on intraannual variations, we now explore how ENSO affects convective activity along the moisture paths to Lhasa.

For this purpose, we use remote sensing information on vapor $\delta \mathrm{D}$, which is expected to show variations similar to vapor $\delta^{18} \mathrm{O}$ in the TP (He et al. 2015). The retrieved vapor $\delta \mathrm{D}$ from TES at $680 \mathrm{hPa}$ and the simulated vapor $\delta \mathrm{D}$ from the zoomed LMDZiso model at $680 \mathrm{hPa}$

\footnotetext{
$\leftarrow$

2007 and 2006. (e) Difference in averaged JJAS precipitation amount from GPCP between 2005 and 2006. (f) As in (e), but for 2007 and 2006. (g) Difference in averaged JJAS OLR between 2005 and 2006. (h) As in (g), but for 2007 and 2006. (i) Difference in precipitation amount along the moisture transport paths between 2005 and 2006. (j) As in (i), but for 2007 and 2006. Moisture transport paths are shown as red, green, and blue curves in Figs. 2b-d. Starting point of moisture transport paths is the location of Lhasa, marked as distance 0 . (k) Difference in JJAS $\delta \mathrm{D}_{v}$ at $680 \mathrm{hPa}$ from zoomed LMDZiso simulations along the moisture transport paths between 2005 and 2006. (l) As in (k), but for 2007 and 2006.
} 
are compared in the 2006 El Niño year, the 2007 La Niña year, and the 2005 normal year. Figures $3 \mathrm{a}$ and $3 \mathrm{~b}$ show that the vapor $\delta \mathrm{D}_{v}$ is about $20 \%$ lower at Lhasa in the La Niña year than in the El Niño year. During the La Niña year, $\delta \mathrm{D}_{v}$ is much higher in the NWI and in the west Indian Ocean, and at the same time a little higher in southeast China than in the El Niño year (Fig. 3b). However, more depleted $\delta \mathrm{D}_{v}$ appears in the west Indian Ocean and BOBA in the normal year than in the El Niño year (Fig. 3a). Those patterns are also captured in the LMDZiso simulations during the normal year (Fig. 3c), but the simulations failed in the tropical Indian Ocean during the La Niña year (Fig. 3d). This indicates that enriched $\delta \mathrm{D}_{v}$ appears in the west Indian Ocean and the Bay of Bengal during the La Niña year but not in the normal year. During the La Niña year, much more precipitation occurs in the southern TP and in northern India, especially along the Himalayas, and in the Arabian Sea, and more precipitation occurs in the Bay of Bengal than during the El Niño year (Fig. 3f). However, less precipitation occurs in Bangladesh and the Arabian Sea during the normal year than during the El Niño year (Fig. 3e). This indicates that more precipitation occurs from NWI and a portion of BOBA during the La Niña year than in other years.

The spatial patterns of OLR are remarkably different between the El Niño year and the La Niña year, supporting our finding. During the normal year, a bit stronger convection appears in the southern TP and in northern India than in the El Niño year (Fig. 3g). In the La Niña year, stronger deep convection appears in the Bay of Bengal, the South China Sea, and the Indian Ocean around Indonesia than in the El Niño year, while weaker convection appears in the Arabian Sea and the western region of the Indian Ocean, which is associated with enriched $\delta \mathrm{D}_{v}$ (Figs. $3 \mathrm{~b}$ and $3 \mathrm{~h}$ ). This indicates that 1 ) weaker convection in the Bay of Bengal and the eastern region of the Indian Ocean results in reduced precipitation and less depleted vapor during the 2006 El Niño year and 2) reduced precipitation in northern India and along the Himalayas in the southern region of the TP further contributes to less depleted vapor isotopes at Lhasa during the El Niño year compared with the La Niña year.

The discrepancy of precipitation amount and $\delta^{18} \mathrm{O}_{v}$ along the three moisture transport paths confirm the ENSO impacts. The distance is calculated from Lhasa along trajectory paths. Less precipitation occurs along BOBA from 1800 to $800 \mathrm{~km}$ during the La Niña year, but the opposite condition exists during the normal year (Figs. 3i and 3j). More than $50 \mathrm{~mm}$ of precipitation occurs along NTP in 2007 compared with 2005 between 200 and $1200 \mathrm{~km}$, and NWI shows opposite variations between the La Niña year and the normal year. NTP and NWI $\delta^{18} \mathrm{O}_{v}$ show remarkable differences from 1400 to
$700 \mathrm{~km}$ between the La Niña year and the normal year, and the fast depletion of NTP and NWI $\delta^{18} \mathrm{O}_{v}$ intensified the lower amount of $\delta^{18} \mathrm{O}_{v}$ during the La Niña year (Figs. 3k and 31). Considering the corresponding BOBA $\delta^{18} \mathrm{O}_{v}$, we deduced that the convection along BOBA dominates the differences in $\delta^{18} \mathrm{O}_{v}$ between the La Niña year and other years from the tropical Indian Ocean to Lhasa, and the more depleted $\delta^{18} \mathrm{O}_{v}$ from NWI intensifies the depleted $\delta^{18} \mathrm{O}_{p}$ at Lhasa.

\section{Conclusions}

Based on 10 years of event-based precipitation sampling at Lhasa, we investigated the relationship between ENSO indices and summer $\delta^{18} \mathrm{O}_{p}$ interannual variations. We confirmed earlier studies based on ice core records and concluded a discernable ENSO influence that explains more than $60 \%$ of the interannual Lhasa summer $\delta^{18} \mathrm{O}_{p}$ variations. No relationships are shown between summer $\delta^{18} \mathrm{O}_{p}$, the local precipitation amount effect, and the surface air temperature, at the interannual scale. The satellite data and LMDZiso simulations confirmed the difference in vapor and precipitation stable isotopes between the $\mathrm{El}$ Niño year and the La Niña year. We strengthened the earlier conclusions on the role of regional upstream convection activity on south Tibet summer $\delta^{18} \mathrm{O}_{p}$ previously identified at the intra-annual scale (Gao et al. 2013) and concluded a similar mechanism affects the relationship between the interannual scale and ENSO teleconnections. Because of the large deviation of annual $\delta^{18} \mathrm{O}_{p}$ between in situ observations and simulations before 2002, we did not use simulations and TES data to extend the ENSO teleconnections directly. It is noted that 2006 was a weak El Niño event and assessing the robustness of this mechanism will require analyses on multiple $\mathrm{El} \mathrm{Niño} \mathrm{and} \mathrm{La}$ Niña events, in order to account for the decadal variability of teleconnections. For this purpose, a network of long-term monitoring of precipitation and vapor isotopic composition as well as sustained remote sensing of tropospheric vapor isotopic composition will be greatly needed. One should be cautious when using our results to explain the long-term mechanisms, and the possible extension of our results is limited by the obvious deviation appearing among the in situ observations and simulations from 1997 to 2001. Because of a lack of a comparison between in situ observations that are not available after 2007 and satellite data, more TES data covering more ENSO events are not probed in this study.

Our results also have implications for the climatic interpretation of oxygen isotope records extracted from the southern TP natural archives, such as ice cores, tree rings, lake sediments, and speleothems. The spatial heterogeneity of variations from nearby ice core records (Gao 
et al. 2016) may arise from the complex patterns of moisture transport pathways and underlying variations in the integrated precipitation amount, convective activity, and the influence of ENSO along these pathways. Moreover, they also have implications for past ENSO reconstructions (e.g., McGregor et al. 2010). Provided that methodologies are developed to extract the ENSO fingerprint from networks of seasonally resolved proxy records in the southern Tibetan Plateau, new information may be available to strengthen past reconstructions of ENSO variance and associated teleconnections.

Acknowledgments. This work was funded by the National Natural Science Foundation of China (Grants 41471053 and 41190080), the Youth Innovation Promotion Association of the CAS (2014061), the Strategic Priority Research Program (B) of the Chinese Academy of Sciences (XDB03030100), and the Caiyuanpai program. We acknowledge the important contribution of Camille Risi from LMD/IPSL for the LMDZiso simulation and two anonymous reviewers, whose comments and suggestions greatly improved the manuscript. We also thank the staff at the Tibet observation stations for collecting the precipitation samples and for taking simultaneous notes, and the staff for measuring the samples. The wind data used in this publication are available online (http://www.esrl.noaa.gov/psd/data).

\section{REFERENCES}

Annamalai, H., K. Hamilton, and K. R. Sperber, 2007: The South Asian summer monsoon and its relationship with ENSO in the IPCC AR4 simulations. J. Climate, 20, 1071-1092, https:// doi.org/10.1175/JCLI4035.1.

Ashok, K., Z. Guan, and T. Yamagata, 2001: Impact of the Indian Ocean dipole on the relationship between the Indian monsoon rainfall and ENSO. Geophys. Res. Lett., 28, 4499-4502, https:// doi.org/10.1029/2001GL013294.

- _ - N. H. Saji, and T. Yamagata, 2004: Individual and combined influences of ENSO and the Indian Ocean dipole on the Indian summer monsoon. J. Climate, 17, 3141-3155, https:// doi.org/10.1175/1520-0442(2004)017<3141:IACIOE>2.0.CO;2.

Boschat, G., P. Terray, and S. Masson, 2011: Interannual relationships between Indian summer monsoon and Indo-Pacific coupled modes of variability during recent decades. Climate Dyn., 37, 1019-1043, https://doi.org/10.1007/s00382-010-0887-y.

Cai, Z., and L. Tian, 2016: Atmospheric controls on seasonal and interannual variations in the precipitation isotope in the East Asian monsoon region. J. Climate, 29, 1339-1352, https://doi.org/10.1175/JCLI-D-15-0363.1.

Draxler, R. R., and G. D. Hess, 1998: An overview of the HYSPLIT_4 modelling system for trajectories, dispersion, and deposition. Aust. Meteor. Mag., 47, 295-308.

Fan, L., S.-I. Shin, Z. Liu, and Q. Liu, 2016: Sensitivity of Asian Summer Monsoon precipitation to tropical sea surface temperature anomalies. Climate Dyn., 47, 2501-2514, https:// doi.org/10.1007/s00382-016-2978-x.
Felton, C. S., B. Subrahmanyam, and V. S. N. Murty, 2013: ENSOmodulated cyclogenesis over the Bay of Bengal. J. Climate, 26, 9806-9818, https://doi.org/10.1175/JCLI-D-13-00134.1.

Fu, R., A. D. Del Genio, and W. B. Rossow, 1990: Behavior of deep convective clouds in the tropical Pacific deduced from ISCCP radiances. J. Climate, 3, 1129-1152, https://doi.org/10.1175/ 1520-0442(1990)003<1129:BODCCI > 2.0.CO;2.

Gao, J., V. Masson-Delmotte, T. Yao, L. Tian, C. Risi, and G. Hoffmann, 2011: Precipitation water stable isotopes in the south Tibetan Plateau: Observations and modeling. J. Climate, 24, 3161-3178, https://doi.org/10.1175/ 2010JCLI3736.1.

,-- C. Risi, Y. He, and T. Yao, 2013: What controls precipitation $\delta 18 \mathrm{O}$ in the southern Tibetan Plateau at seasonal and intra-seasonal scales? A case study at Lhasa and Nyalam. Tellus, 65B, 21043, https://doi.org/10.3402/tellusb.v65i0.21043.

, C. Risi, V. Masson-Delmotte, Y. He, and B. Xu, 2016: Southern Tibetan Plateau ice core $\delta{ }^{18} \mathrm{O}$ reflects abrupt shifts in atmospheric circulation in the late 1970s. Climate Dyn., 46, 291-302, https://doi.org/10.1007/s00382-015-2584-3.

Gates, W. L., 1992: AMIP: The Atmospheric Model Intercomparison Project. Bull. Amer. Meteor. Soc., 73, 1962-1970, https://doi.org/10.1175/1520-0477(1992)073<1962:ATAMIP>2.0. $\mathrm{CO} ; 2$.

Girishkumar, M. S., and M. Ravichandran, 2012: The influences of ENSO on tropical cyclone activity in the Bay of Bengal during October-December. J. Geophys. Res., 117, C0203, https://doi.org/10.1029/2011jc007417.

— V. P. Thanga Prakash, and M. Ravichandran, 2015: Influence of Pacific Decadal Oscillation on the relationship between ENSO and tropical cyclone activity in the Bay of Bengal during October-December. Climate Dyn., 44, 3469-3479, https://doi.org/10.1007/s00382-014-2282-6.

Goswami, B. N., and P. K. Xavier, 2005: ENSO control on the south Asian monsoon through the length of the rainy season. Geophys. Res. Lett., 32, L18717, https://doi.org/10.1029/ $2005 \mathrm{gl} 1023216$.

He, Y., and Coauthors, 2015: Impact of atmospheric convection on south Tibet summer precipitation isotopologue composition using a combination of in situ measurements, satellite data, and atmospheric general circulation modeling. J. Geophys. Res. Atmos., 120, 3852-3871, http://doi.org/ 10.1002/2014JD022180.

Huffman, G. J., R. F. Adler, M. M. Morrissey, D. T. Bolvin, S. Curtis, R. Joyce, B. McGavock, and J. Susskind, 2001: Global precipitation at one-degree daily resolution from multisatellite observations. J. Hydrometeor., 2, 36-50, https://doi.org/10.1175/ 1525-7541(2001)002<0036:GPAODD > 2.0.CO;2.

Kalnay, and Coauthors, 1996: The NCEP/NCAR 40-Year Reanalysis Project. Bull. Amer. Meteor. Soc., 77, 437-471, https:// doi.org/10.1175/1520-0477(1996)077<0437:TNYRP>2.0.CO;2.

Keppenne, C. L., and M. Ghil, 1992: Adaptive filtering and prediction of the Southern Oscillation index. J. Geophys. Res., 97, 20 449-20 454, https://doi.org/10.1029/92JD02219.

Klinker, E., F. Rabier, G. Kelly, and J.-F. Mahfouf, 2000: The ECMWF operational implementation of four-dimensional variational assimilation. III: Experimental results and diagnostics with operational configuration. Quart. J. Roy. Meteor. Soc., 126, 1191-1215, https://doi.org/10.1002/qj.49712656417.

Kumar, K. K., B. Rajagopalan, and M. A. Cane, 1999: On the weakening relationship between the Indian monsoon and ENSO. Science, 284, 2156-2159, https://doi.org/10.1126/science.284.5423. 2156. 
Li, X., and M. Ting, 2015: Recent and future changes in the Asian monsoon-ENSO relationship: Natural or forced? Geophys. Res. Lett., 42, 3502-3512, https://doi.org/10.1002/2015GL063557.

Liebmann, B., and C. A. Smith, 1996: Description of a complete (interpolated) outgoing longwave radiation dataset. Bull. Amer. Meteor. Soc., 77, 1275-1277.

Liu, B., G. Wu, and R. Ren, 2015: Influences of ENSO on the vertical coupling of atmospheric circulation during the onset of South Asian summer monsoon. Climate Dyn., 45, 18591875, https://doi.org/10.1007/s00382-014-2439-3.

Mao, J., and G. Wu, 2007: Interannual variability in the onset of the summer monsoon over the Eastern Bay of Bengal. Theor. Appl. Climatol., 89, 155-170, https://doi.org/10.1007/ s00704-006-0265-1.

McGregor, S., A. Timmermann, and O. Timm, 2010: A unified proxy for ENSO and PDO variability since 1650. Climate Past, 6, 1-17, https://doi.org/10.5194/cp-6-1-2010.

Meehl, G. A., and J. M. Arblaster, 2002: Indian monsoon GCM sensitivity experiments testing tropospheric biennial oscillation transition conditions. J. Climate, 15, 923-944, https:// doi.org/10.1175/1520-0442(2002)015<0923:IMGSET>2.0.CO;2.

Rasmusson, E. M., and T. H. Carpenter, 1982: Variations in tropical sea surface temperature and surface wind fields associated with the Southern Oscillation/El Niño. Mon. Wea. Rev., 110, 354-384, https://doi.org/10.1175/1520-0493(1982)110<0354: VITSST $>2.0 . \mathrm{CO} ; 2$.

Rayner, N. A., D. E. Parker, E. B. Horton, C. K. Folland, L. V. Alexander, D. P. Rowell, E. C. Kent, and A. Kaplan, 2003: Global analyses of sea surface temperature, sea ice, and night marine air temperature since the late nineteenth century. J. Geophys. Res., 108, 4407, https://doi.org/10.1029/2002JD002670.

Risi, C., S. Bony, F. Vimeux, and J. Jouzel, 2010: Water-stable isotopes in the LMDZ4 general circulation model: Model evaluation for present-day and past climates and applications to climatic interpretations of tropical isotopic records. J. Geophys. Res., 115, D12118, doi:10.1029/2009JD013255.

Saji, N. H., and T. Yamagata, 2003: Possible impacts of Indian Ocean Dipole mode events on global climate. Climate Res., $\mathbf{2 5}$, 151-169, https://doi.org/10.3354/cr025151.

Sankar, S., M. R. R. Kumar, and C. Reason, 2011: On the relative roles of El Nino and Indian Ocean Dipole events on the monsoon onset over Kerala. Theor. Appl. Climatol., 103, 359374, https://doi.org/10.1007/s00704-010-0306-7.

Soman, M. K., and J. Slingo, 1997: Sensitivity of the Asian summer monsoon to aspects of sea-surface-temperature anomalies in the tropical Pacific Ocean. Quart. J. Roy. Meteor. Soc., 123, 309-336, https://doi.org/10.1002/qj.49712353804.

Thompson, D. W. J., and J. M. Wallace, 1998: The Arctic Oscillation signature in the wintertime geopotential height and temperature fields. Geophys. Res. Lett., 25, 1297-1300, https:// doi.org/10.1029/98GL00950.

Thompson, L. G., K. A. Henderson, E. Mosley-Thompson, and P.-N. Lin, 2000a: The tropical ice core record of ENSO. El
Niño and the Southern Oscillation: Multiscale Variability and Global and Regional Impacts, H. F. Diaz and V. Markgraf, Eds., Cambridge University Press, 325-356, https://doi.org/ 10.1017/CBO9780511573125.010.

T. Yao, E. Mosley-Thompson, M. E. Davis, K. A. Henderson, and P. Lin, 2000b: A high-resolution millennial record of the South Asian Monsoon from Himalayan ice cores. Science, 289, 1916-1920, https://doi.org/10.1126/science.289. 5486.1916.

Tian, L., V. Masson-Delmotte, M. Stievenard, T. Yao, and J. Jouzel, 2001: Tibetan Plateau summer monsoon northward extent revealed by measurements of water stable isotopes. J. Geophys. Res., 106, 28 081-28 088, https://doi.org/10.1029/ 2001JD900186.

—, T. Yao, P. F. Schuster, J. W. C. White, K. Ichiyanagi, E. Pendall, J. Pu, and Y. Wu, 2003: Oxygen-18 concentrations in recent precipitation and ice cores on the Tibetan Plateau. J. Geophys. Res., 108, 4293, doi:10.1029/2002JD002173.

Torrence, C., and P. J. Webster, 1999: Interdecadal changes in the ENSO-monsoon system. J. Climate, 12, 2679-2690, https:// doi.org/10.1175/1520-0442(1999)012<2679:ICITEM>2.0.CO;2.

Vuille, M., and M. Werner, 2005: Stable isotopes in precipitation recording South American summer monsoon and ENSO variability: Observations and model results. Climate Dyn., 25, 401-413, https://doi.org/10.1007/s00382-005-0049-9.

Wang, B., Q. H. Ding, and P. V. Joseph, 2009: Objective definition of the Indian summer monsoon onset. J. Climate, 22, 33033316, https://doi.org/10.1175/2008JCLI2675.1.

Worden, J., S. S. Kulawik, M. W. Shephard, S. A. Clough, H. Worden, K. Bowman, and A. Goldman, 2004: Predicted errors of tropospheric emission spectrometer nadir retrievals from spectral window selection. J. Geophys. Res., 109, D09308, https://doi.org/10.1029/2004JD004522.

_ , and Coauthors, 2006: Tropospheric Emission Spectrometer observations of the tropospheric $\mathrm{HDO} / \mathrm{H}_{2} \mathrm{O}$ ratio: Estimation approach and characterization. J. Geophys. Res., 111, D16309, https://doi.org/10.1029/2005JD006606.

- D. Noone, and K. Bowman, 2007: Importance of rain evaporation and continental convection in the tropical water cycle. Nature, 445, 528-532, https://doi.org/10.1038/ nature 05508 .

Yang, M. X., T. D. Yao, Y. Q. He, and L. G. Thompson, 2000: ENSO events recorded in the Guliya ice core. Climatic Change, 47, 401-409, https://doi.org/10.1023/A: 1005696702385 .

Yao, T., and Coauthors, 2013: A review of climatic controls on delta $\delta 18 \mathrm{O}$ in precipitation over the Tibetan Plateau: Observations and simulations. Rev. Geophys., 51, 525-548, doi:10.1002/rog.20023.

Zhang, C., 1993: Large-scale variability of atmospheric deep convection in relation to sea surface temperature in the tropics. J. Climate, 6, 1898-1913, https://doi.org/10.1175/ 1520-0442(1993)006<1898:LSVOAD>2.0.CO;2. 